\title{
The Taylor Rule and the Sandpile: The Taylor Contribution and Other Matters
}

\author{
Juan L. Valderrábano López, Miguel A. Alonso Neira \\ Departamento de Economía Aplicada I, Facultad de Ciencias Jurídicas y Sociales, Universidad Rey Juan Carlos, Madrid, Spain \\ Email: juanluis.valderrabano@gmail.com
}

How to cite this paper: López, J.L.V. and Neira, M.A.A. (2017) The Taylor Rule and the Sandpile: The Taylor Contribution and Other Matters. Open Journal of Modelling and Simulation, 5, 183-188. https://doi.org/10.4236/ojmsi.2017.54014

Received: July 3, 2017

Accepted: August 7, 2017

Published: August 10, 2017

Copyright @ 2017 by authors and Scientific Research Publishing Inc. This work is licensed under the Creative Commons Attribution International License (CC BY 4.0).

http://creativecommons.org/licenses/by/4.0/

(c) (i) Open Access

\begin{abstract}
The author of the Taylor Rule has provided new evidence about the application of the Sandpile model to his rule. The same findings of the Sandpile model are described in the Taylor paper in agreement with the conclusions of the Sandpile model. That is, that keeping interest rates too low for too long penalizes the economic recovery. On top of that the Sandpile also provides a metric for the severity of the crisis. The same law (Power Law) applies to the size and the duration of the crisis just modifying the order of the distribution paving thus a way for measuring the size of the crisis. According to the NBER data, the length is already determined for the US crisis, if the model holds on, we can also assess the severity.
\end{abstract}

\section{Keywords}

Taylor Rule, Sandpile, Weak Chaos

\section{Background}

Economic bubbles produce a dramatic damage to society due to the lasting consequences of their burst on business and people. Each agency is interested in detecting early signals of a bubble in order to mitigate the consequences but there is not an agreement about how bubbles are produced and the responsibility of each part on it. We can find different approaches, some of them assume that bubbles are triggered or initiated by a specific cause and, therefore, there is a cause-effect relationship. Other approaches assert that bubbles do not exist at all, but reflect the existence of different equilibrium states of the economy. The most structured approach posits that "financial crisis emerges not as the result of specific economic events or regulatory developments, but rather as a result of a long-term evolutionary process that regulates companies' growth-mergers and 
acquisitions." [1]. Other authors suggest that the combined action of public entities, like central banks through liquidity creation measures and interest rate manipulation, can not only produce economic bubbles but also delay and prolong the duration of the subsequent recovery as it has been well documented [2]. It seems that in some cases there is a strong connection between the working of the monetary and financial system, when deceiving the economic agents by artificially altering the interest rate or by creating an excess of liquidity, and boombust business cycles. The Taylor Rule is a sound guide used by central banks to set up interest rates and most of all, it is an objective tool that the market can know and use in advance to forecast inflation and interest rates, instead of guessing. This makes it easier for economic agents to work and therefore provides more stability to the markets.

In searching for ways and means to prevent economic bubbles or at least to temper them, we considered ideas from other fields of Science. In [3] and [4], we established a link between the Taylor Rule used in Economics and Complex behavior (Weak Chaos) used in Physical and Biological Systems. Our hypothesis is that dynamical systems in different areas of human activity, when sharing a common statistic at macro level are also likely to share a structure at micro level. This is so because they share a class of phenomena.

As E. O. Wilson points out [5]:

"The current status of the social sciences can be put in perspective by comparing them with medical sciences. Both have entrusted with big urgent problems. Medical scientists are paid for example to cure cancer correct genetic birth defects, and repair severed nerve cords: Social scientists are expected to tell us how moderate ethnic conflict, convert developing countries into prosperous democracies and optimize world trade. In both spheres problems have been intractably complex, partly because the root causes are poorly understood."

Now, by means of the Sandpile model, we look to set up a parallelism between both situations, that is to say, the manipulation of interest rates by central banks, the excess liquidity measures, and the burst of the bubbles. We can set a parallelism first with the working of the Sandpile model: how grains pile up until a critical condition is overcome and the ensuing pile relaxation, because both systems share a global stat, the Power Law that links the size with the number of relaxations of the pile (avalanches). We do that by interpreting the Taylor Rule and the constraints imposed by the neoclassical IS-LM model in terms of the evolution of liquidity and interest rates.

Earlier [3] [4], we have interpreted the Taylor Rule as a weak chaos example. We even provided a near fit with the Power Law distribution using the available data for T-bonds distribution for the US as an example, assuming that when two systems (the Sandpile and the T-bonds) share a common stat, the underlying phenomena respond to the same structural properties.

This idea is not alien. We must remember that a young British man named Harold Edwin Hurst became Abu Nil or Father of Nile river in the early XXth 
century because he was able to predict the size of Nile flooding by means of a formula that years after, in the sixties, B. Mandelbrot discovered that it could also be applied to the fluctuations of the New York Stock Exchange [6]. In particular, the observations of the flow from a Gaussian point of view presented what we can call outliers because there was a drought in the period 1913-1914, followed by a similar one two years later. Interestingly, climate gust was producing the alterations in the pattern that up to that moment could be explained by a Gaussian law. We refer to the text to reinforce the idea that the Power Law statistic was shared between a collection of collaborative phenomena, in which not only mattered the flood size but also the precise sequence. This permits us to infer that a common structure is beyond the observed.

As it is usual when building up theories, in the early stages the connections with the theory and the experience is rather weak. We link two classes of facts as described by its probability function. We study a model of how weak chaos can help to interpret economic bubbles. We go on relying on the data provided by a former book [7] about housing bubbles that provided twofold evidence. First because we used the same literal expressions when describing the burst of the housing bubble as we did for the avalanches in the Sandpile model, with the effects of the burst as an avalanche. Second, because we built a critical condition to overcome as a triggering fact in the Sandpile model that was fully in agreement with the supporting causes of the housing bubble as already explained in [4]. This means plainly that the external (exogenous) intervention on the economic variables, the rate of interest and the liquidity measures, was against of what was required by the IS-LM model for stability.

Now, as time goes by, new evidence supporting the parallelism further between both, the Sandpile model and the Taylor Rule gushes up and, what it is more important, this parallelism is brought by the very same designer of the Taylor Rule when studying the last crisis in the US.

Let me recall some of the undertakings of other sciences such as Geology to illustrate the way to come. It is very interesting to navigate in other disciplines and to know what happened in earlier times. Let's take a look to a comment [8] of which Darwin was an admirer while comparing the achievements of Geology and Astronomy:

"Whether our investigation of the earth's history and structure will eventually be productive of as great practical benefits to mankind as a knowledge of the distant heavens, must remain for the decision of posterity. It was not till astronomy had been enriched by the observations of many centuries and had made its way against popular prejudices to the establishment of a sound theory that its application to the useful arts was more conspicuous. The cultivation of geology early began at a later period; and in every step which he has hitherto made towards sound theoretical principles it has had to control against more violent prepossessions. The practical advantages already derived from it have not been inconsiderable, but our generalizations are yet imperfect and they who follow may be expected to reap the most valuable fruits of our labor. Meanwhile the 
charm of first discovery is our own, and as we explore this magnificent field of inquiry the sentiment of a great historian of our times may continually be present to our minds that "he who calls what has vanished back again into being, enjoys a bliss like that of creating".

This was said between 1830 and 1833 and we could be in a similar position today in Economics.

\section{Taylor Contribution}

In an early paper [2], J. Taylor studies the period 2000-2007 for the US economy and sets up several conclusions in agreement with the available data. He states:

"I have provided empirical evidence that government actions and interventions caused, prolonged and worsened the financial crisis. They caused it by deviating from historical precedents and principles and setting interest rates, which have worked well for 20 years. They prolonged it by misleading the problems in the bank credit markets and thereby responding inappropriately by focusing on liquidity than risk. They made it worse by providing support for certain financial institutions and their creditors but not to others in an ad hoc way without a clear and understandable framework. While other factors were certainly at play, these government actions should be first on the list of answers to the question of what went wrong."

Later in a second paper there is another contribution from the same author, encompassing a later period (2006-2010) where he identifies several failures that can be summarized as: "You are really hard pushed to see that the stimulus package stimulated consumption and thereby stimulated the economy" [9] concerning the 2008 stimulus and the 2009 stimulus. Lastly Taylor asserts: "for the US, I saw monetary policy in 2003-2004 and 2005 hold interest rates too low for too long" (p. 9). The last sentence is in full agreement with what we have forecasted.

\section{Sandpile Findings}

It was already pointed out that there is a strong correlation between the Sandpile model and the IS-LM model, in particular for the expression linking the change of the interest rate and the liquidity. In [4], we emphasized that the violation of the restriction imposed between the change in the interest rate and the liquidity was the triggering fact needed to cause an avalanche, an economic burst in this case. Both actions, the liquidity measures and the interest rate intervention, were acting oppositely causing trouble or even making the system collapse. One of the measures-setting up a target for the interest rate-and the other-the introduction of new liquidity facilities-were acting one against the other according to the equations of the IS-LM model.

\section{Duration of the Crisis}

As stated [10], there is a connection between the duration of the avalanches and 
its size and this fact is of great importance for the problem of economic bubbles. So we have two outcomes, that is, the causes for the bust and the duration of the process. In this respect, economists know there is not a shared measure of the severity of the crisis other than the length and the depth of the recessionary cycles. As it is documented for the US by the NBER data and the paper already mentioned, sets up for the duration of the process, another potential law with a lower exponent of one degree less. Accordingly, assuming that the data on the duration of the economic crisis obeys a potential distribution, we can estimate that the related severity would be described by a likely law with one degree less. Perhaps the economic bodies and authorities can set a standard for this.

\section{Conclusions and Discussion}

We can draw two kinds of lessons from the already accumulated experience. One comes from [7] and the other from the paper of Taylor [9]. In the first case, we have a compatible global view of the problem that is housing bubbles that we can assimilate to the global picture of the Sandpile model according to the narrative. In the second case, we can connect the change in the interest rate and the increasing liquidity measures, with both being opposite to each other, as a clear example of the triggering fact. The bursting of the bubbles was similar to violating a stability condition in the Sandpile model. On top of that, both situations share a global statistic as we have seen in the T-bonds example.

Regarding the information provided by Taylor, he fully endorses the results of the lessons of the Sandpile in terms of the triggering fact. Interest rate intervention and increasing liquidity measures are poisonous for the recovery because they act oppositely. We can assert that according to two well established sources, the book on housing bubbles and the Taylor paper, both the ideas and the data, fit in with the Sandpile model.

Last but not least, it is necessary to emphasize a clear fact. The Sandpile model fits with the view of an external observer. It is not built from a detailed point of view assembling the mutual interactions of each piece of sand with the others, to get the global picture. We are not even interested in the physical or chemical properties of the grains of sand. It is irrelevant when studying the equilibrium of the Sandpile. The laws of the global equilibrium are of a different nature as the local one. Then from this point of view, a main weakness of this theory is the inability to connect the micro and macro levels. In this case, what we do is to observe it as a class of phenomena in the edge of criticality that happens in the surface of the Sandpile without inner connection to the rooting causes. This is not a flaw specific of this discipline, but rather a general issue in an emerging science.

\section{Acknowledgements}

We want to thank to the family Sole Parellada-Martín del Moral for their support in the elaboration of this article. 


\section{References}

[1] Jeldtoft, H., West, G. and Viegas, E. (2014) The Wall Street Jungle, Deconstructed. New Scientist, 224, 28-29. https://doi.org/10.1016/S0262-4079(14)62094-7

[2] Taylor, J. (2008) The Financial Crisis and the Policy Responses: What Went Wrong. NBER Working Paper 14631, National Bureau of Economic Research.

[3] López, J.L.V. and Alonso Neira, M.Á. (2015) A Lecture of the Taylor Rule from the Sandpile Model. Open Journal of Modelling and Simulation, 3, 19-25. https://doi.org/10.4236/ojmsi.2015.31002

[4] López, J.L.V. and Alonso Neira, M.Á. (2015) The Taylor Rule and the Sandpile: A Former Paper's Review. Open Journal of Modelling and Simulation, 3, 191-195. https://doi.org/10.4236/ojmsi.2015.34018

[5] Wilson, E.O. (1998) Consilience. Alfred A. Knopf, New York, 181 p.

[6] Mandelbrot, B. (2004) The (MIS) Behaviour of Markets. A Fractal View of Risk, Ruin and Reward. Profile Books Ltd., London.

[7] Gjerstad, S.D. and Smith, V. (2014) Rethinking Housing Bubbles: The Role of Household and Bank Balance Sheets in Modeling Economic Cycles. Cambridge University Press, Cambridge. https://doi.org/10.1017/CBO9780511979194

[8] Lyell, C. (1997) Principles of Geology. Penguin Classics, London, 25.

[9] Taylor, J.B. (2013) Getting off Track: How Government Actions and Interventions Caused, Prolonged, and Worsened the Financial Crisis. Hoover Press, Hoover Institution, Stanford University, Stanford, CA.

[10] Bak, P. and Paczuski, M. (1995) Complexity, Contingency and Criticality. Proceedings of the National Academy of Sciences of the United States of America, 92, 66896696. https://doi.org/10.1073/pnas.92.15.6689

\section{Submit or recommend next manuscript to SCIRP and we will provide best} service for you:

Accepting pre-submission inquiries through Email, Facebook, LinkedIn, Twitter, etc. A wide selection of journals (inclusive of 9 subjects, more than 200 journals)

Providing 24-hour high-quality service

User-friendly online submission system

Fair and swift peer-review system

Efficient typesetting and proofreading procedure

Display of the result of downloads and visits, as well as the number of cited articles

Maximum dissemination of your research work

Submit your manuscript at: http://papersubmission.scirp.org/

Or contact ojmsi@scirp.org 